\title{
Mission Advantages of NEXT: NASA's Evolutionary Xenon Thruster
}

Steven Oleson, Leon Gefert, Scott Benson, and Michael Patterson Glenn Research Center, Cleveland, Ohio

Muriel Noca and Jon Sims

Jet Propulsion Laboratory, Pasadena, California 
Since its founding, NASA has been dedicated to the advancement of aeronautics and space science. The NASA Scientific and Technical Information (STI) Program Office plays a key part in helping NASA maintain this important role.

The NASA STI Program Office is operated by Langley Research Center, the Lead Center for NASA's scientific and technical information. The NASA STI Program Office provides access to the NASA STI Database, the largest collection of aeronautical and space science STI in the world. The Program Office is also NASA's institutional mechanism for disseminating the results of its research and development activities. These results are published by NASA in the NASA STI Report Series, which includes the following report types:

- TECHNICAL PUBLICATION. Reports of completed research or a major significant phase of research that present the results of NASA programs and include extensive data or theoretical analysis. Includes compilations of significant scientific and technical data and information deemed to be of continuing reference value. NASA's counterpart of peerreviewed formal professional papers but has less stringent limitations on manuscript length and extent of graphic presentations.

- TECHNICAL MEMORANDUM. Scientific and technical findings that are preliminary or of specialized interest, e.g., quick release reports, working papers, and bibliographies that contain minimal annotation. Does not contain extensive analysis.

- CONTRACTOR REPORT. Scientific and technical findings by NASA-sponsored contractors and grantees.
- CONFERENCE PUBLICATION. Collected papers from scientific and technical conferences, symposia, seminars, or other meetings sponsored or cosponsored by NASA.

- SPECIAL PUBLICATION. Scientific, technical, or historical information from NASA programs, projects, and missions, often concerned with subjects having substantial public interest.

- TECHNICAL TRANSLATION. Englishlanguage translations of foreign scientific and technical material pertinent to NASA's mission.

Specialized services that complement the STI Program Office's diverse offerings include creating custom thesauri, building customized databases, organizing and publishing research results ... even providing videos.

For more information about the NASA STI Program Office, see the following:

- Access the NASA STI Program Home Page at http://www.sti.nasa.gov

- E-mail your question via the Internet to help@sti.nasa.gov

- Fax your question to the NASA Access Help Desk at 301-621-0134

- Telephone the NASA Access Help Desk at 301-621-0390

- Write to: NASA Access Help Desk NASA Center for AeroSpace Information 7121 Standard Drive Hanover, MD 21076 


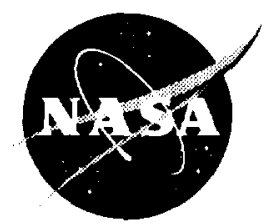

\section{Mission Advantages of NEXT: NASA's Evolutionary Xenon Thruster}

Steven Oleson, Leon Gefert, Scott Benson, and Michael Patterson

Glenn Research Center, Cleveland, Ohio

Muriel Noca and Jon Sims

Jet Propulsion Laboratory, Pasadena, California

Prepared for the

38th Joint Propulsion Conference and Exhibit

cosponsored by the AIAA, ASME, SAE, and ASEE

Indianapolis, Indiana, July 7-10, 2002

National Aeronautics and

Space Administration

Glenn Research Center 
Available from

NASA Center for Aerospace Information 7121 Standard Drive

Hanover, MD 21076
National Technical Information Service 5285 Port Royal Road Springfield, VA 22100

Available electronically at http://gltrs.grc.nasa.gov 


\title{
MISSION ADVANTAGES OF NEXT: NASA'S EVOLUTIONARY XENON THRUSTER
}

\author{
Steven Oleson. Leon Gefert. Scott Benson. and Michael Patterson \\ National Aeronautics and Space Administration \\ Glenn Research Center \\ Cleveland, Ohio

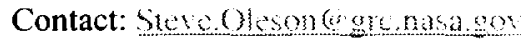 \\ Muriel Noca and Jon Sims \\ Jet Propulsion Lab \\ California Institute of Technology \\ Pasadena, California
}

With the demonstration of the NSTAR propulsion system on the Deep Space One mission. the range of the Discovery class of NASA missions can now be expanded. NSTAR lacks. however. sufficient performance for many of the more challenging Office of Space Science (OSS) missions. Recent studies have shown that NASA's Evolutionary Xenon Thruster (NEXT) ion propulsion system is best choice for many exciting potential OSS missions including outer planet exploration and inner solar system sample returns. The NEXT system provides the higher power, higher specific impulse and higher throughput required by these science missions.

\section{Introduction}

With the demonstration of the NSTAR propulsion system on the Deep Space One mission. the range of the NASA Discovery class of missions can now be expanded. NSTAR lacks. however. sufficient performance for many of the more challenging Office of Space Science (OSS) missions. Recent studies have shown that NASA's Evolutionary Xenon Thruster (NEXT) ion propulsion system is best choice for many exciting potential OSS missions including outer planet exploration and inner solar system sample returns.

The NEXT system provides quicker missions, delivers heavier payloads. and reduces complexity compared to NSTAR and other options while exhibiting redundancy. de-rating. and optimal $I_{\mathrm{sp}}$. The key improvements over NSTAR, embodied in the NEXT system, are higher power and lower specific mass, and to a lesser extent higher $I_{\mathrm{sp}}$. Specific potential OSS missions where the NEXT system is applicable are outer planet missions: Neptune Orbiter, Titan Explorer. Europa lander. Europa Subsurface, Saturn Ring Observer; and inner solar system missions: Venus Sample Return, Comet Nucleus Sample Return. and Mars Sample Return.

The NEXT ion propulsion system was recently chosen to be developed by the Next Generation Ion (NGI) NASA Research Announcement (NRA) competition. The NEXT propulsion system will be developed over the next few years to a technology level ready to be injected into a flight development program. Mission analyses similar to those shown in this paper are undergoing to support the development of the final design to be developed. Due to these further mission analyses the final NEXT ion propulsion system design may be different than the proposed design discussed in this paper.

An outline of this work is as follows. First the proposed NEXT ion propulsion is described and modeled. followed by the modeling of the solar electric propulsion (SEP) spacecraft. The mission analysis methodology and assumptions are then explained. After a discussion of past specific mission analyses. the design reference missions included in the NGI NRA and their assumptions are described. Finally, mission performance for some other SEP missions using the NEXT ion propulsion system are briefly reviewed. 


\section{$\underline{\text { System Analyses }}$}

\section{Propulsion Systems}

A team of analysts, technologists and engineers from Glenn Research Center (GRC), the Jet Propulsion Lab (JPL), Boeing Electron Dynamic Devices (BEDD), and General Dynamics (GD formerly Primex Aerospace) developed the propulsion system analysis models of the NEXT propulsion system for the mission trades.

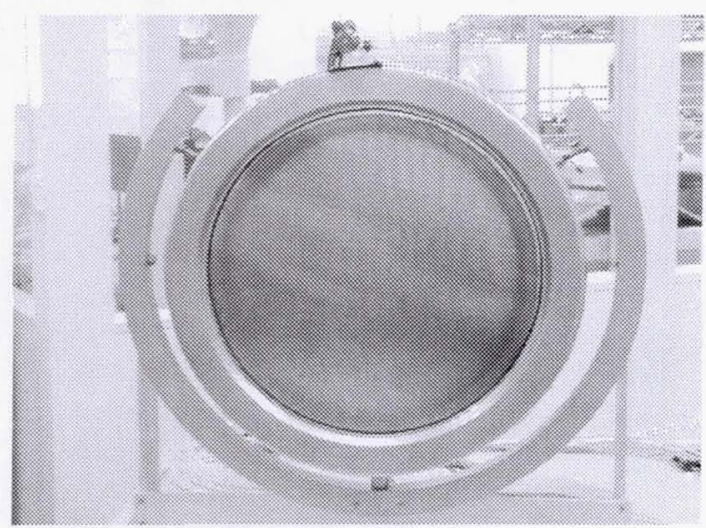

Figure 1. NASA's Evolutionary Xenon Thruster

The NEXT ion propulsion system is assumed to consist of several main components including the thruster (figure 1), the gimbal, the power processing unit (PPU), the digital control interface unit (DCIU), and the feed system (split into a main component and a per engine component). ${ }^{1}$ The estimated system masses are shown in table 1 . The propellant tank is assessed with the spacecraft. Structure and thermal support of the propulsion system subsystems is handled by the spacecraft and modeled with the rest of the subsystems.

Table 1. NEXT Propulsion System Masses

\begin{tabular}{|l|}
\hline $\begin{array}{l}\text { NEXT Propulsion System Masses for Mass each } \\
\text { DSDRM }\end{array}$ \\
\hline (kg)
\end{tabular}

Since the NEXT system is being developed for solar powered interplanetary spacecraft where power level varies with distance from the Sun some amount of power throttling will be required of the system. The NEXT system will be designed for operation with input powers from 1 $\mathrm{kW}$ up to perhaps as high as $10 \mathrm{~kW}$. The throttle table used in the analysis is shown in Table 2 .

With proper PPU design the NEXT thruster should be capable of a limited range of $I_{s p}$ throttling at each power point. The limits of this throttling are noted as High $\mathrm{I}_{\mathrm{sp}}$ and High Thrust in figure 2. Mission analyses traded these limiting throttle curves to determine which was most appropriate for each mission. Current analysis techniques are unable to allow throttling throughout the range at each power level. However, new techniques have recently been developed and are currently being used to support the development of the thruster.

Table 2. NEXT Throttle Table

\begin{tabular}{|llll|}
\hline NEXT Nominal THROTTLE TABLE \\
\hline $\begin{array}{l}\text { Power into Thrust (mN) } \\
\text { PPU (W) }\end{array}$ & $\begin{array}{l}\text { Total } \\
\text { Propulsion } \\
\text { System } \\
\text { Efficiency } \\
\text { (thruster } \\
\text { PPU) }\end{array}$ & $\begin{array}{l}\text { Specific } \\
\text { Impulse (s) }\end{array}$ \\
\hline 10.5 & 364 & 0.67 & 3940 \\
8.60 & 299 & 0.67 & 3900 \\
6.38 & 221 & 0.66 & 3870 \\
4.91 & 170 & 0.65 & 3860 \\
2.28 & 76 & 0.61 & 3760 \\
\hline 7.75 & 282 & 0.66 & 3680 \\
5.73 & 209 & 0.65 & 3660 \\
4.42 & 160 & 0.65 & 3630 \\
2.07 & 71 & 0.60 & 3550 \\
\hline 4.97 & 192 & 0.64 & 3360 \\
3.82 & 147 & 0.63 & 3340 \\
1.81 & 65 & 0.58 & 3250 \\
\hline 3.37 & 137 & 0.62 & 3110 \\
1.61 & 61 & 0.56 & 3020 \\
\hline 1.17 & 49 & 0.51 & 2460 \\
\hline
\end{tabular}


Due to the high specific impulse of ion propulsion systems, long burn times (years) are needed to provide the required mission energy (velocity change or $\mathrm{V}$ ). This challenge to create a long-lived propulsion system was a major part of the NSTAR development (including a ground life test) and will be integral to the development of the NEXT thruster. Analyses have shown that throughput lifetimes for the NEXT thruster should be at least $300 \mathrm{~kg}$. if not more. The mission analyses adjusted the number of thrusters to handle the required throughput.

To demonstrate the need and advantages of the NEXT system the missions were also evaluated using the state-of-art $2.3 \mathrm{~kW}$ ion thruster NSTAR (flown on Deep Space 1), as well as a high $\mathrm{I}_{\mathrm{sp}} 30 \mathrm{~cm}$ ion propulsion system analyzed in the Integrated In-Space Transportation Planning (IISTP) studies (hereafter denoted as the IISTP$5 \mathrm{~kW}-30 \mathrm{~cm}$ ). Mass, throttle and life information on the NSTAR and the IISTP- $5 \mathrm{~kW}-30 \mathrm{~cm}$ was obtained from the NRA and the IISTP analysis, respectively. ${ }^{2.3}$

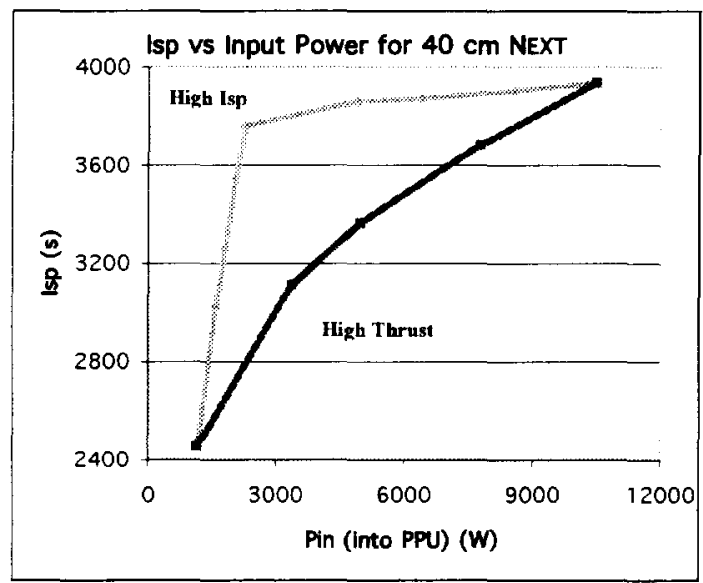

Figure 2. High $I_{s p}$ and High Thrust Throttle Fits

\section{Solar Electric Propulsion Spacecraft}

The rest of the SEP spacecraft, such as the solar array, thermal system, and structure, were modeled using a spacecraft model developed during the JPL integrated project design center (Team X) analysis of the Titan Explorer mission for the IISTP. 3.4.5.6 Glenn Research Center and Marshall Space Flight Center supported this exercise with technology analysis and mission support. The propulsion subsystem is integrated into the spacecraft using this model.
To be consistent with the JPL conceptual design guidelines used in the IISTP analysis, $30 \%$ mass and $30 \%$ power contingencies were applied to all spacecraft subsystems, and a 10\% launch vehicle margin was assumed. The structures/cabling masses are not based on a specific design but are a percentage of the subsystems to which the structures apply (typically $26 \%$ of the propulsion system and $16 \%$ of the power system for structures). These percentages are based on historical data and are consistent with the design guidelines of Team X. However. the structural mass includes additional mass to carry the spacecraft above the SEP stage to overcome launch loads, mass to hold the tanks. mass for the SEP stage separation mechanism and additional mass for the system assembly hardware (bolts. epoxies. tie downs...). The payload spacecraft side of the launch vehicle adapter is also included in the SEP stage structure.

One spare ion engine for every four operating ion engines and one spare PPU and digital control interface unit (DCIU) are included for single-fault tolerance. Each thruster was gimbaled separately.

The tankage fraction was calculated assuming cylindrical composite tanks. Those tanks have a propellant storage efficiency (Tank Fraction TF) of about $2.5 \%$ for Xenon when stored as a supercritical gas ( 2000 psia). Furthermore, a $10 \%$ propellant contingency was added to the deterministic propellant mass to account for residuals. attitude control and margin. Other assumptions are as follows:

SEP Stage Assumptions

Minimum two thrusters operating (actual number optimized [but 2 or greater] by SEPTOP code)

Spare Thruster and PPU Added

Delta IV $M+(4,2)$ Launcher

Common. 100VDC Solar Array

$5 \%$ Fuel added and expended during flight for errors and misc.

$5 \%$ Fuel reserve added

$10 \%$ Trajectory Management Coast Time

$174 \mathrm{~W} / \mathrm{kg}$ Ultraflex Solar Arrays (150 W/kg with structure)

Power System Specific Mass: $9.2 \mathrm{~kg} / \mathrm{kW}$

Power and Thermal Structure: $16 \%$

Thermal control per PPU : $24 \mathrm{~kg} / \mathrm{kWthermal}$

Stage Cabling (Not PPU) : $6 \%$ of Power Mass

Tankage Mass Fraction (includes Structure $26 \%$ dry. $4 \%$ fuel ] and $5 \%$ residual fuel ): $15.6 \%$

Structure to Support Payload Spacecraft on SEP Stage $85 \%$ of Payload mass

Spacecraft Adapter: $42 \mathrm{~kg}$

Launch Vehicle Adapter: $65 \mathrm{~kg}$ 
Alternate Ion propulsion systems

c NSTAR SOA: Masses and Performance from DSDRM (reference 2) except advanced tanks used with NEXT

C. IISTP $5 \mathrm{~kW} 30 \mathrm{~cm}$ : Mass and Performance Data from Reference 3. (IlSTP Analyses) and advanced Tanks used with NEXT

\section{Mission Analyses}

Once the propulsion system has been modeled in terms of mass and performance and incorporated into a spacecraft model its delivered payload mass and required trip time can be determined using a trajectory optimization code. The code of choice for this analysis was the Solar Electric Propulsion Trajectory Optimization Program (SEPTOP) developed by Carl Sauer of JPL. SEPTOP is a calculus-of-variations code which optimizes two body interplanetary trajectories. SEPTOP models discrete numbers of operating xenon thrusters throughout a trajectory. The number of operating thrusters is switched by SEPTOP in an optimal fashion. Additionally, SEPTOP throttles the thrusters in power as required by that available from the Sun. SEPTOP was used to evaluate trades of delivered payload and trip time.

In order to examine trades of payload mass payload versus trip time. the SEPTOP code needs a simplified system mass model. A top level mass equation was developed which was derived from the Team $\mathrm{X}$ modeling for input into SEPSPOT:

$$
\begin{gathered}
M_{\text {Launch }}=M_{\text {Adapter }}+\alpha_{\text {Power }} P+M_{\text {SEP-Fixed }}+ \\
M_{\text {Pavioad }}\left(1+k_{\text {Stucture }} M_{\text {Payload }}\right)+ \\
M_{\text {Pr opellani }}\left(1+k_{\text {Tankage }} M_{\text {Payload }}\right)
\end{gathered}
$$

where.

$$
\begin{aligned}
& M_{\text {Launch }}=\text { Total Launch Mass }(\mathrm{kg}) \\
& \mathrm{M}_{\text {Adapter }}=\text { LV Adapter Mass }(\mathrm{kg}) \\
& \mathrm{M}_{\text {Payload }}=\text { Science Payload Mass }(\mathrm{kg}) \\
& \mathrm{M}_{\text {Propellanl }}=\text { Xenon Propellant }(\mathrm{kg}) \\
& \alpha_{\text {Power }}=\text { Specific Power Mass }(\mathrm{kg} / \mathrm{kW}) \\
& \text { [determined by component mass summation] } \\
& \mathrm{k}_{\text {Struture }}=\text { Payload Structure Fraction }(\%) \\
& \mathrm{k}_{\text {Tamkage }}=\text { Propellant Storage Fraction }(\%) \\
& \mathrm{M}_{\text {SEP-Fixed }}=\text { Fixed Mass }(\mathrm{kg}) \\
& \mathrm{P}=\text { Array } 1 \text { A.U. Power }(\mathrm{kW})
\end{aligned}
$$

The values of $k_{\text {structure. }} k_{\text {tankage. }} P$ are set to $8.5 \%$. $15.6 \%$ and $25 \mathrm{~kW}$ (from DSDRM assumptions) respectively. The linear scaling factors $\mathrm{k}_{\text {structure. }}$ $k_{\text {tankage }}$ and $n_{\text {Power }}$ model the rate in which their systems functionally grow and $\mathrm{M}_{\text {SEP-Fixed }}$ includes the fixed masses of systems that do not grow as a function of other parameters.

\section{$\underline{\text { Mission Trades }}$}

ISTP Studies

Previous to the release of the NGI NRA, the Integrated In-Space Transportation Planning (IISTP) studies compared many potential technologies for various NASA, government and commercial missions. ${ }^{3.45 .0}$ These studies indicated that a high power ion propulsion system (of which NEXT was one of the samples) is the most important technology for development due to its outstanding performance versus perceived development and recurring costs for interplanetary solar electric propulsion missions. One of the best applications of a high power electric propulsion system was as an integral part of a Solar Electric Propulsion (SEP) stage to send a payload to outer planet targets which would use aeroshells to capture into the outer planetary orbits. ${ }^{4} \quad$ The IISTP studies showed that either trip time or launch vehicle class can be significantly reduced when compared to state-of-the-art systems. ${ }^{45.6}$

Deep Space Design Reference Mission Studies The SEP stage mission developed for the IISTP studies is very similar to the Deep Space Design Reference Missions (DSDRMs) defined in the NRA. The main difference was that the DSDRMs had greater desired payloads. The role of the DSDRMs was to allow proposers to demonstrate their concept's ability to perform missions of interest. ${ }^{2}$ Thus to show the advantages of the NEXT ion thruster for the DSDRM missions, JPL and Glenn Research Center analysts used the SEPTOP numerical optimization code (previously used for the IISTP analyses) to evaluate the NEXT's performance for two outer planet missions: Titan Explorer and Neptune Orbiter. These two missions represent targets at Saturn or closer, and beyond Saturn. respectively, as desired in the DSDRM. In order to quantify the mission benefits of the NEXT ion propulsion system analyses were run to determine the mission performance using SOA NSTAR systems. An additional approach was also analyzed (similar to that in the IISTP analyses). that of a $30 \mathrm{~cm}$ thruster at $5 \mathrm{~kW} .3 .4 .5 .0$ 
Table 3. Summary of DSDRM Inputs for SEPTOP

\begin{tabular}{|c|c|c|c|c|c|c|}
\hline $\begin{array}{c}\text { DSDRM } \\
\text { Spacecraft } \\
\text { Assumptio } \\
\text { ns } \\
\text { [SEPTOP } \\
\text { Inputs] }\end{array}$ & $\bar{x}$ & $\underbrace{\frac{\alpha}{2}}_{0} \underset{0}{ }$ & 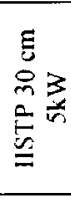 & $\begin{array}{l}\bar{x} \\
\text { I } \\
z\end{array}$ & 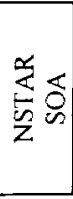 & $\begin{array}{l}E \\
0 \\
0 \\
0 \\
\vdots \\
\vdots\end{array}$ \\
\hline Target & \multicolumn{3}{|c|}{ Neptune } & \multicolumn{3}{|c|}{ Saturn } \\
\hline $\begin{array}{c}\text { \# Thrusters } \\
\text { \# PPUs }\end{array}$ & $4 / 4$ & $9 / 9$ & $6 / 6$ & $3 / 3$ & 919 & $5 / 5$ \\
\hline $\begin{array}{c}\text { Fixed mass } \\
\text { [kg] (Dry } \\
\text { SEP Stage } \\
\text { less power } \\
\text { \& Tanks) } \\
\text { [alfa(2)] }\end{array}$ & 601 & 696 & 570 & 501 & 696 & 510 \\
\hline $\begin{array}{l}\text { Payload } \\
\text { [alfa( } 7)]\end{array}$ & \multicolumn{3}{|c|}{850} & \multicolumn{3}{|c|}{1400} \\
\hline $\begin{array}{l}\text { Payload } \\
\text { Structure } \\
\text { Fraction } \\
[\text { alfa( } 8)]\end{array}$ & \multicolumn{3}{|c|}{0.085} & \multicolumn{3}{|c|}{0.085} \\
\hline $\begin{array}{c}\text { Tankage } \\
\text { (include } \\
\text { structure \& } \\
5 \% \\
\text { Residua]) } \\
{[\mathrm{kt}]} \\
\end{array}$ & .156 & .28 & .15 & 15 & .28 & .15 \\
\hline $\begin{array}{l}\text { Power } \\
\text { System } \\
\text { Specific } \\
\text { Mass } \\
\text { (kg/kW) } \\
[\text { alfa( } 1)]\end{array}$ & \multicolumn{3}{|c|}{9.2} & \multicolumn{3}{|c|}{9.2} \\
\hline
\end{tabular}

The DSDRM clearly defined the power and payload spacecraft to be assumed for each mission. A total solar array power of $30 \mathrm{~kW}$ is provided at Earth's orbital distance from the Sun but only $25 \mathrm{~kW}$ maximum power was to be available to the propulsion system, allowing 5 $\mathrm{kW}$ for housekeeping and reserve. As the spacecraft journeys closer to the Sun to flyby Venus the arrays are assumed to be manipulated to cap the power to the propulsion system at 25 kW. The payload orbiter spacecraft with its aerocapture system was assumed to be $850 \mathrm{~kg}$ and $1400 \mathrm{~kg}$ for the Neptune (past Saturn example) and Titan Orbiter (Saturn and closer example), respectively. After the specific SEP stage parameters were calculated by the design model they were interpreted into those required by the SEPTOP model as described earlier. These parameters are shown in table 3. Each of the DSDRM missions and the analysis results will now be described.

\section{Neptune Orbiter}

Placing an orbiter around Neptune is of great interest after the tantalizing views sent back by

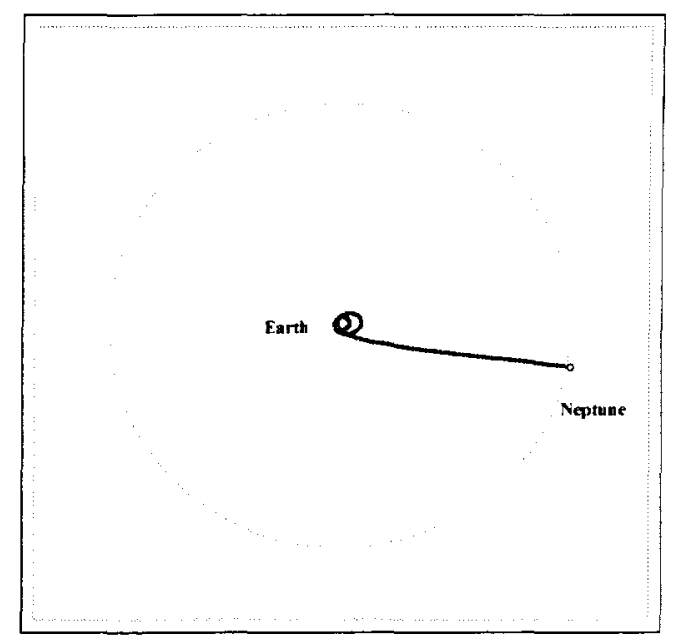

Figure 3. Neptune Orbiter Trajectory

Voyager. The SEP system 's role for the mission is that of a stage to build up energy in the inner solar system. redirect the energy with a Venus flyby and separate the radioisotope powered Neptune orbiter on a fast trajectory to Neptune. Once at Neptune an advanced aeroshell system is used to capture in orbit.

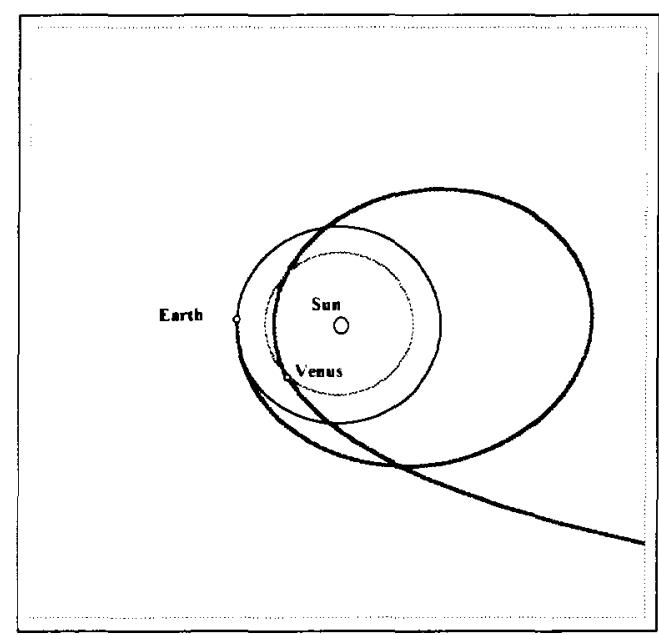

Figure 4. SEP Portion of Neptune Orbiter Trajectory

A sample trajectory' for the SEP stage is shown in figure 3. The SEP stage provides a very fast path to Neptune after the Venus flyby. A closer view of the inner solar system trajectory showing the Venus flyby is shown in figure 4 . Since the available power varies as the spacecraft moves closer to and further from the sun before and after the Venus flyby, the number of thrusters which may be operated varies. This variation of power and operating thrusters is shown in figure 5. The number of operating thrusters in this case varies 4-3-2-3-4-3-2 thrusters as power varies with solar distance. 


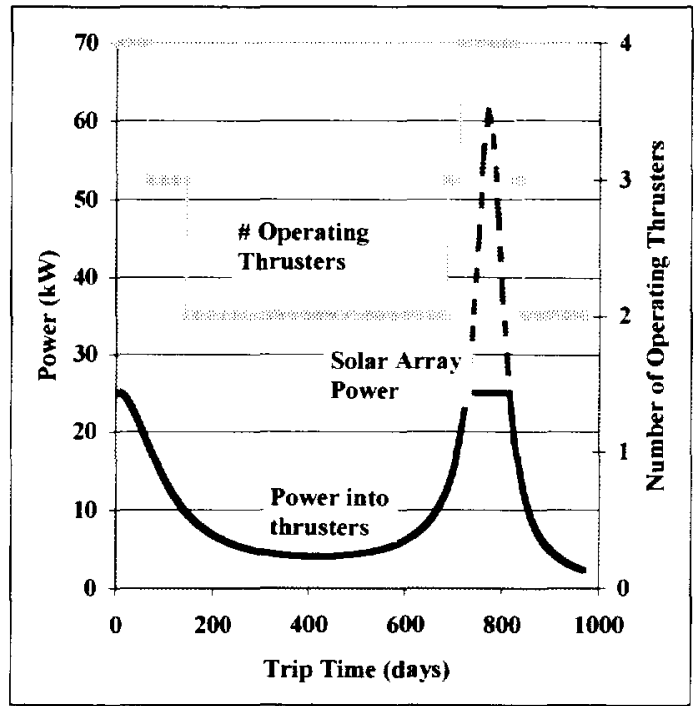

Figure 5. Power and Operating Thruster Variation with Thrust Time

Maximum power into the propulsion system was set by the DSDRM at $25 \mathrm{~kW}$. Note however, when the spacecraft approaches Venus the potential power level exceeds this power. A small study was performed to see if this additional power (up to $40 \mathrm{~kW}$ ) would be beneficial to the mission, but the additional power management mass to deliver the power to the thrusters offset any benefits. This result was reasonable due to the relatively short time the power is available. When the power falls to around $2 \mathrm{~kW}$ at the end of the inner solar system portion of the trajectory the propulsion system is shut down since the minimum throttled thruster power is $1 \mathrm{~kW}$.

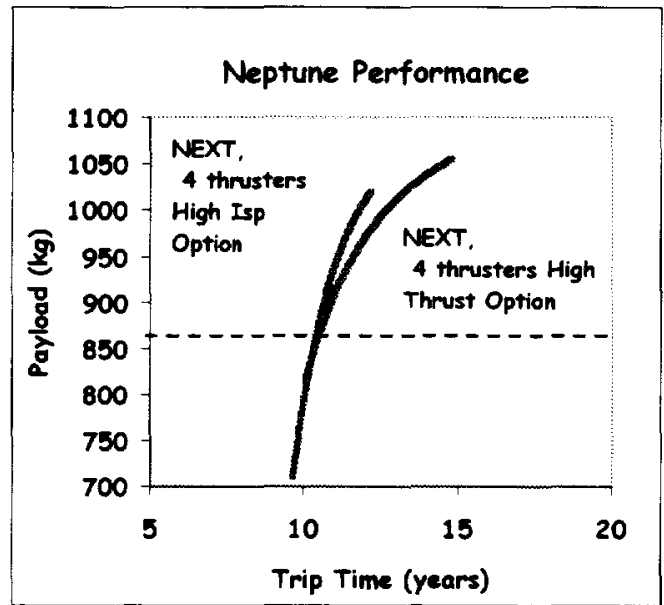

Figure 6. Performance Trade of High $I_{3 p}$ and High Thrust NEXT Options
Before comparing the NEXT propulsion system performance to that of the other ion systems a comparison was made of the performance of the High $I_{\text {sp }}$ and High Thrust throttle options shown in figure 1. Results are shown in figure 6. While both systems delivered the required payload in roughly the same time, the high thrust option was slower for higher payload masses. Since most science payloads tend to grow in mass the high $I_{\mathrm{sp}}$ option was chosen as superior and used for the rest of the analyses.

Results shown in figure 7 for the Neptune Orbiter mission clearly show the trip time advantages of the NEXT system versus the other systems. Such savings in trip time can save $>\$ 5$ million a year in operations costs for missions in addition to allowing scientific investigators more timely research. The use of fewer thrusters should also result in a cost savings as well as a reduced complexity. The SOA NSTAR system is hampered by its low power capability. necessitating an exorbitant propulsion system dry mass. The IISTP- $5 \mathrm{~kW}-30 \mathrm{~cm}$ system has too high an $I_{\text {sp }}$ and must rely upon the launch vehicle to perform more of the mission (higher excess velocity [C3]. less mass at escape) than for the NEXT ion propulsion system case.

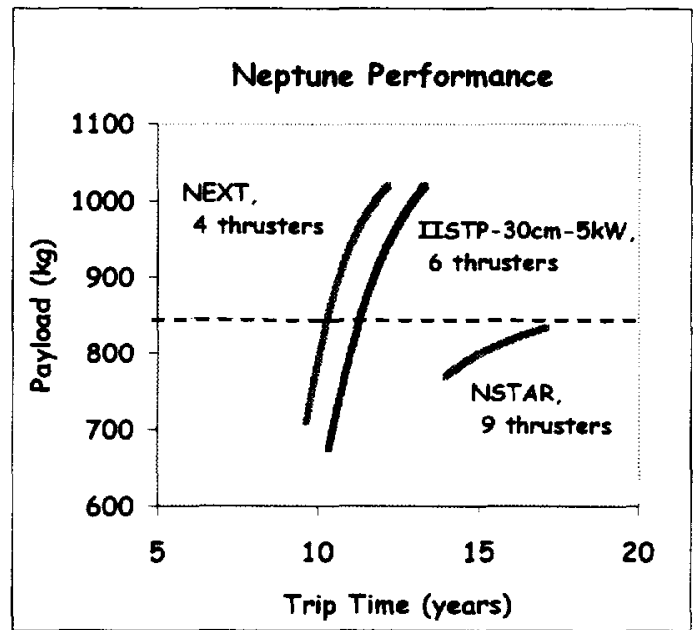

Figure 7. Neptune Performance Trade of Ion Propulsion Options

The NEXT system performance results shown are for a 4 thruster / 4 PPU case where the power is capped at $25 \mathrm{~kW}$ as directed in the DSDRM. For the desired $850 \mathrm{~kg}$ payload the 4 thruster configuration's maximum power level and fuel throughput (for each thruster/PPU) is decidedly derated at $6.25 \mathrm{~kW}$ and just under $200 \mathrm{~kg}$. respectively. If a thruster or PPU fails the mission can be easily completed with only three 
thrusters at a still derated performance of $8.3 \mathrm{~kW}$ and $260 \mathrm{~kg}$. This clearly demonstrates the NEXT thrusters are not oversized for the mission and consequently will have plenty of growth potential for even higher power missions.

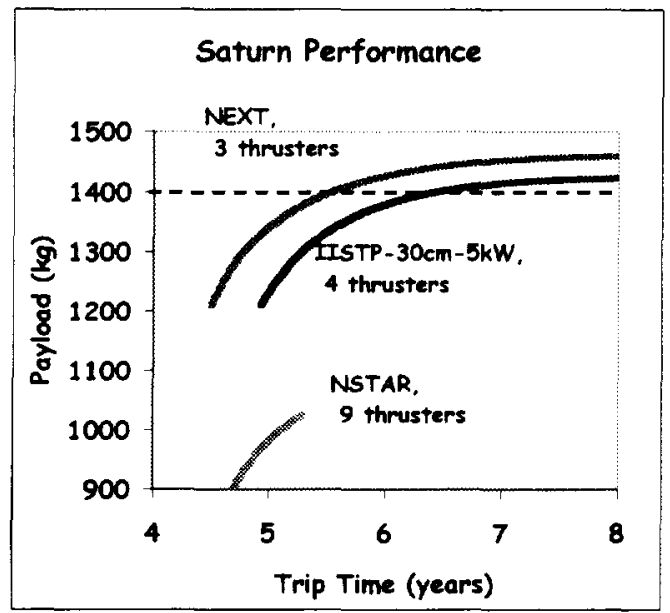

Figure 8. Saturn (Titan) Performance Trade Ion Propulsion Options

\section{Titan Explorer}

The other DSDRM mission analyzed used a similar SEP Venus flyby trajectory to place an aerocapture orbiter about Saturn's moon Titan. The trajectories and throttling requirements for Titan look similar to those for the Neptune orbiter.

Applying the NEXT ion propulsion technology to the Titan Explorer mission showed slightly different results (figure 8.). The larger $1400 \mathrm{~kg}$ desired payload began to stress the assumed launch vehicle with the required performance moving past the knee of the performance (payload versus trip time) curve. Regardless, the NEXT system is again a year quicker than the IISTP-5KW-30 CM system and the SOA NSTAR is unable to deliver the required payload.

\section{Comet Sample Return}

Returning samples from a comet are also of great interest. Use of SOA NSTAR for a Comet Return mission would require too many thrusters (9) due to the limited power capability, making the delivered mass performance poor. A study using the NEXT ion propulsion system was made using the same models developed for the DSDRM missions. Results showed that almost $25 \%$ greater payload could be carried. Use of the NEXT would also greatly reduce the complexity of the $30 \mathrm{~kW}$ SEP spacecraft by reducing the number of thrusters from 9 NSTAR to 4 NEXT (both concepts include spares).

\section{Mars Sample Return}

The NEXT technology can also be applied to other NASA missions to great effect. Returning samples from solar system targets is of particular interest to scientists. A recent study. conducted by JSC. Spectrum Astro, and SAIC. explored the use of SEP for a Mars sample return mission (these trades used assumptions different than those of the DSDRM missions, but are representative). ${ }^{7}$ The SEP system was traded for various phases of the mission from just returning the sample from low Mars orbit to performing all of the interplanetary and near planet propulsion. Using a Delta II class launch vehicle a $10 \mathrm{~kW}$ SEP spacecraft equipped with two NEXT thrusters returned the Mars sample in a total transit time of 4 years ( 2 years Mars to Earth): the lander and Mars ascent vehicle (to place the sample into Mars orbit) would be launched by another launch vehicle. Use of a $40 \mathrm{~kW}$ SEP spacecraft along with six NEXT thrusters could perform the entire mission. delivery of orbiter and lander and return of the samples in 4.9 years round trip using a Delta 4 Heavy launch vehicle. To perform this mission using chemical SOA and aerocapture would require two Atlas V 551 medium class launch vehicles. In these cases the NEXT proved useful in both the $10 \mathrm{~kW}$ and $40 \mathrm{~kW}$ SEP spacecraft cases, demonstrating the wide range of application of the technology.

\section{Commercial Geostationary}

The NEXT is also advantageous to governmental and commercial geosynchronous missions. Currently. Boeing is using four $4.5 \mathrm{~kW}$ ion thrusters for both orbit insertion and station keeping of their $17 \mathrm{~kW} 702$ spacecraft. As power levels of the spacecraft grow the larger ion propulsion systems such as NEXT will be able to provide payload increases of at least $50 \%$ for a few months trip times. ${ }^{8}$ With sufficient power $(40 \mathrm{~kW})$ it should be possible to provide a launch vehicle step-down for trip times of less than six months."

\section{Conclusions}

These trade studies. while not encompassing all potential missions, clearly demonstrate the advantages of the NEXT system for NASA outer planet. sample return. and interplanetary missions, as well as commercial earth orbit missions. Compared to the SOA NSTAR the NEXT provides a higher power, lighter, longer 
life system which can be used for a wide range of SEP power levels. The NEXT can provide quicker trip times for better science and cheaper missions. Mission trades were made to evaluate the best way to throttle the thruster and the use of extra power at Venus was also considered.

\section{References}

1. M. Patterson. J. Foster, T. Haag, V. Rawlin and G. Soulas. NEXT: NASA's Evolutionary Xenon Thruster. AIAA-2002-3832, 2002 Joint Propulsion Conference. Indianapolis. Indiana. July 2002.

2. NASA Research Announcement for the Next Generation Ion Engine Technology, NRA-01OSS-01, section A.9.2.

3. Noca, M.. Frisbee, R.. Johnson. L., Kos, L.. Gefert. L.. Dudzinski, L.. Evaluating Advanced Propulsion Systems for the Titan Explorer Mission. IEPC-01-175, 27 $7^{\text {th }}$ IEPC, Oct. 2001. Pasadena. CA.

4. Integrated In-Space Transportation Planning (IISTP). Summary of Process and Technology Prioritization. May 30, 2001. (contact Larry Kos, MSFC. 256 544-1522)
5. Neptune Orbiter Mission Package. In-Space Integrated Space Transportation Activity by the IISTP Systems Analysis Team. Apr. 4 $4^{\text {th }} 2001$. (contact Larry Kos. MSFC. 256 544-1522)

6. Titan Explorer Mission. In-Space Integrated Space Transportation Activity, Team X/A Results. Apr. 19 ${ }^{\text {th }}, 2001$. (Muriel Noca)

7. SEP for Mars Sample Return, MPSET Status Briefing. Dec. 5. 2001. (Contact Jeff George. NASA/JSC)

8. Oleson, S.R., Myers, R.M., Launch Vehicle and Power Level Impacts on Electric GEO Insertion, 32nd Joint Propulsion Conference, July, 1996. AIAA-96-2978, NASA Contractor Report 198520.

9. Oleson. S.R., Advanced Electric Propulsion for RLV Launched Geosynchronous Spacecraft, , 26th International Electric Propulsion Conference, Kitakyushu, Japan, October. 1999. IEPC 99-185. 
Public reporting burden for this collection of information is estimated to average 1 hour per response, including the time for reviewing instructions. searching existing data sources gathering and maintaining the data needed, and completing and reviewing the collection of information. Send comments regarding this burden estimate or any other aspect of this

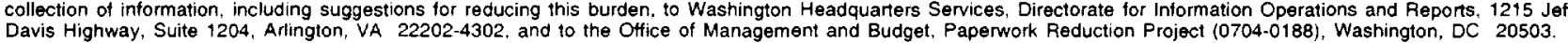

\begin{tabular}{|l|l|l|l|}
\hline 1. AGENCY USE ONLY (Leave blank) & $\begin{array}{r}\text { 2. REPORT DATE } \\
\text { September } 2002\end{array}$ & $\begin{array}{r}\text { 3. REPORT TYPE AND DATES COVERED } \\
\text { Technical Memorandum }\end{array}$ \\
\hline 4. TITLE AND SUBTITLE
\end{tabular}

\section{TITLE AND SUBTITLE}

Mission Advantages of NEXT: NASA's Evolutionary Xenon Thruster

6. AUTHOR(S)

WU-344-96-8D-00

Steven Oleson, Leon Gefert. Scott Benson, Michael Patterson, Muriel Noca, and Jon Sims

7. PERFORMING ORGANIZATION NAME(S) AND ADDAESS(ES)

National Aeronautics and Space Administration

John H. Glenn Research Center at Lewis Field

Cleveland, Ohio 44135-3191

8. PERFORMING ORGANIZATION REPORT NUMBER

E-13574

9. SPONSORING/MONITORING AGENCY NAME(S) AND ADDRESS(ES)

10. SPONSOAINGMONITORING

National Aeronautics and Space Administration

Washington, DC 20546-0001 AGENCY REPORT NUMBER

NASA TM-2002-211892

AIAA-2002-3969

\section{SUPPLEMENTARY NOTES}

Prepared for the 38th Joint Propulsion Conference and Exhibit cosponsored by the AIAA. ASME, SAE, and ASEE. Indianapolis. Indiana, July 7-10, 2002. Steven Oleson, Leon Gefert. Scott Benson, and Michael Patterson, NASA Glenn Research Center; Muriel Noca and Jon Sims, Jet Propulsion Laboratory, California Institute of Technology, Pasadena, California. Responsible person, Steven Oleson, organization code 6910, 216-977-7426.

12a. DISTRIBUTION/AVAILABILITY STATEMENT 12b. DISTRIBUTION CODE

Unclassified - Unlimited

Subject Categories: 13, 20, and 91

Distribution: Nonstandard

Available electronically at hetp:/igltrs gric nasa.gov

This publication is available from the NASA Center for AeroSpace Information. 301-621-0390.

13. ABSTRACT (Maximum 200 words)

With the demonstration of the NSTAR propulsion system on the Deep Space One mission, the range of the Discovery class of NASA missions can now be expanded. NSTAR lacks, however, sufficient performance for many of the more challenging Office of Space Science (OSS) missions. Recent studies have shown that NASA's Evolutionary Xenon Thruster (NEXT) ion propulsion system is the best choice for many exciting potential OSS missions including outer planet exploration and inner solar system sample returns. The NEXT system provides the higher power, higher specific impulse, and higher throughput required by these science missions.

14. SUBJECT TERMS

Ion propulsion; Electric propulsion; Planetary spacecraft
15. NUMBER OF PAGES

14

16. PAICE CODE

\begin{tabular}{|c|c|}
\hline $\begin{array}{c}\text { 17. SECURITY CLASSIFICATION } \\
\text { OF REPORT }\end{array}$ & $\begin{array}{c}\text { 18. SECURITY CLASSIFICATION } \\
\text { OF THIS PAGE } \\
\text { Unclassified }\end{array}$ \\
Unclassified
\end{tabular}

NSN 7540-01-280-5500
19. SECURITY CLASSIFICATION OF ABSTRACT

Unclassified
20. LIMITATION OF ABSTRACT 